\title{
Early Holocene morphological variation in hunter-gatherer hands and feet
}

\author{
Kara C Hoover ${ }^{\text {Corresp., }}{ }^{1}$, J Colette Berbesque ${ }^{2}$ \\ ${ }^{1}$ Department of Anthropology and Department of Biochemistry and Molecular Biology, University of Alaska, Fairbanks, Alaska, United States \\ ${ }^{2}$ Centre for Research in Evolutionary, Social and Inter-Disciplinary Anthropology, University of Roehampton, London, United Kingdom \\ Corresponding Author: Kara C Hoover \\ Email address: kchoover@alaska.edu
}

Background. The Windover mortuary pond dates to the Early Archaic period $(6,800-5,200$ years ago) and constitutes one of the earliest archaeological sites with intact and wellpreserved human remains in North America. Unlike many prehistoric egalitarian huntergatherers, the Windover people may not have practiced a sex-based division of labor, rather they may have shared the load. We explore how mobility and subsistence, as reconstructed from archaeological data, influenced hand and foot bone morphology at Windover. Methods. We took length and width measurements on four carpal bones, four tarsal bones, and load-bearing tarsal areas (calcaneus load arm, trochlea of the talus). We analyzed lateralization using side differences in raw length and width measurements. For other hypothesis testing, we used log transformed length-width ratios to mitigate the confounding effects of sexual dimorphism and trait size variation; we tested between-sex differences in weight-bearing (rear foot) and shock-absorbing (mid foot) tarsal bones and between-sex differences in carpal bones. Results. We identified no significant betweensex differences in rear and midfoot areas, suggesting similar biomechanical stresses. We identified no significant between-sex differences in carpal bones but the test was underpowered due to small sample sizes. Finally, despite widespread behavioral evidence on contemporary populations for human hand and foot lateralization, we found no evidence of either handedness or footedness. Discussion. The lack evidence for footedness was expected due its minimal impact on walking gait but the lack of evidence for handedness was surprising given that ethnographic studies have shown strong handedness in huntergatherers during tool and goods manufacture. The reconstructed activity patterns suggested both sexes engaged in heavy load carrying and a shared division of labor. Our results support previous findings-both sexes had stronger weight-bearing bones. While male shock-absorbing bones exhibited a trend towards greater relative width (suggesting greater comparative biomechanical stress), this may simply some lingering hunting behavior with males walking greater distances at higher speeds than females. While there 
were no significant between-sex differences in carpal bones (supporting a shared work load model), females exhibited greater variation in index values, which may reflect a greater variety of and specialization in tasks compared to males. Because carpals and tarsals are so well-preserved at archaeological sites, we had surmised they might be useful proxies for activity in the absence of well-preserved long bones. Tarsals provide a stronger signal of past activity and may be useful in the absence or, or in addition to, preferred bones. Carpals, however, may not be useful as the effect size of biomechanical stress (in this study at least) is low and would require larger samples than may be possible at archaeological sites. 
1 Early Holocene morphological variation in hunter-gatherer hands and feet

2

\author{
Kara C. Hoover ${ }^{1 *}$ \\ J. Colette Berbesque ${ }^{2}$ \\ ${ }^{1}$ Department of Anthropology, University of Alaska Fairbanks, Fairbanks Alaska USA, \\ kchoover@alaska.edu \\ ${ }^{2}$ Centre for Research in Evolutionary, Social and Inter-Disciplinary Anthropology, University of \\ Roehampton, London UK Colette.Berbesque@roehampton.ac.uk \\ *Corresponding author \\ Running title: Hunter-Gatherer Hands and Feet
}

\section{Abstract}

Background. The Windover mortuary pond dates to the Early Archaic period (6,800-5,200 years ago) and constitutes one of the earliest archaeological sites with intact and well-preserved human remains in North America. Unlike many prehistoric egalitarian hunter-gatherers, the Windover people did not practice a sex-based division of labor, rather they shared the load. We explore how mobility and subsistence, as reconstructed from archaeological data, influenced hand and foot bones morphology at Windover.

Methods. We took length and width measurements on four carpal and four tarsal bones. We also took length and width measurements on tarsal load-bearing areas (calcaneus load arm and trochlea of the talus). We analyzed lateralization in these elements using side differences in raw length and width measurements. For other hypothesis testing, we used log transformed length-width ratios to mitigate the confounding effects of sexual dimorphism and trait size variation; we tested between-sex differences in weight-bearing and shock-absorbing tarsal bones and between-sex differences in carpal bones.

Results. We identified no significant between-sex differences in the rear (weight-bearing) and midfoot (shock-absorbing) regions, suggesting similar biomechanical stresses acting on the tarsal bones. Carpal bones were not significantly different between males and females but the test was under-powered due to small sample sizes. Finally, despite widespread behavioral evidence on contemporary populations for human lateralization for hands and feet, we found no evidence of either handedness or footedness in Windover.

Discussion. The lack evidence for footedness was expected due its minimal impact on walking gait but the lack of evidence for handedness is surprising given that modern ethnographic studies have shown strong handedness in hunter-gatherers during tool and goods manufacture. The reconstructed activity patterns of Windover males and females suggested both sexes engaged in heavy load carrying and a shared division of labor. Our results support previous findings. Further, both sexes had stronger weightbearing bones. Finally, male shock-absorbing bones exhibited a trend towards greater relative width (suggesting greater comparative biomechanical stress) than females which may reflect the typical pattern of male hunter-gatherers engaging in walking greater distances at higher speeds than females. While there were no significant between-sex differences in carpal bones (which reflects male domestic activity based on grave good analysis and a shared work load model), females exhibited greater variation in their index values (which may reflect a greater variety of and specialization in tasks compared to males). Because carpals and tarsals are so well-preserved at archaeological sites, we had surmised they might be useful proxies for activity in the absence of well-preserved long bones. Tarsals provide a greater signal of past activity and may be useful in the absence or, or in addition to, preferred bones. Carpals, however, may not be useful for activity reconstruction as the effect size of bone remodeling due to activity (in this study at least) is low and would require larger samples than may be possible at archaeological sites. 
A sex-based division of labor is seen across most human societies for the majority of evolutionary history and contributes to size-based morphological variation between the sexes (Frayer 1980; Frayer \& Wolpoff 1985). The wealth of ethnographic data on extant hunter-gatherers provides insights into the sexual division of foraging labor. Applying what we know about extant hunter-gatherer behavior to the bioarchaeological record, we can link musculoskeletal markers to habitual activities. Physical markers of activity include geometric variation in bone structure and function due to biomechanical loading (Ruff et al. 2006), diaphyseal structure (Bridges 1989; Bridges 1995; Ruff 1987b; Ruff 1987c; Schaffler et al. 1985), degenerative joint disease (DJD), osteoarthritis, musculoskeletal markers (MSM) (Eshed et al. 2004), and dental wear patterns relative to tool manufacture (Berbesque et al. 2012; Estalrrich \& Rosas 2015). Our specific focus is on the relationship between biomechanics and bone functional adaptation in carpal and tarsal bones. Bone functional adaptation is driven by two general principles: first, organisms are able to structurally adapt to new living conditions; second, bone cells have capacity to respond to local mechanical stresses (Ruff et al. 2006). We draw on the various markers of physical activity to inform our biomechanical approach and previous studies on other skeletal elements in the population of interest but limit our investigation to bone functional adaptation assessed by length-width ratios, which provide an index that can be used to compare relative bone strength (Garn 1972; Rauch 2005). Width is an indicator of relative bone strength (Garn 1972; Rauch 2005) because resistance to bending force is linked to bone diameter; bones functionally adapt to biomechanical stress by forming new bone on periosteal surfaces, which results in wider bones (Macdonald et al. 2013). To the best of our knowledge, this paper is the first to examine the utility of carpal and tarsal metrics as evidence for bone functional adaptation to activity.

\section{Aims}

The focus of this paper is to explore whether or not logistical mobility and domestic economies (subsistence and tool manufacture) are archaeologically visible in the feet (tarsals) and hands (carpals) and, if so, whether or not they reflect a sex-based division of labor. Specifically, we are interested in bone functional adaptation in response to biomechanical stress and use logged length-width ratios to assess relative bone strength (Garn 1972; Macdonald et al. 2013; Rauch 2005). We also examine lateralization using raw measures for left and right sides. Much attention has been paid to sexual dimorphism in carpal and tarsal bones in forensic contexts and with applications to sex identification bioarchaeology; these studies have had varied success with most pointing to the calcaneus and sometimes talus as the most diagnostic bones (Bostanci 1962; Bunning 1964; Gualdi-Russo 2007; Harris \& Case 2012; Hoover 1997; Introna et al. 1997; Kidd \& Oxnard 2002; Mastrangelo et al. 2011a; Mastrangelo et al. 2011b; Riepert et al. 1996; Steele 1970; Steele 1976; Steele \& McKern 1969)_for a review see (Davies et al. 2014). Here, we take a different approach by exploring whether activity is embodied in the often overlooked region of the hands and feet.

Carpals and tarsals have not been examined extensively in bioarchaeological contexts but are potentially very interesting bones. The hands and feet are heavily implicated in the daily activities of huntergatherers (e.g., mobility, use of weapons, tool-making, domestic economies) and that activity might be embodied in carpal and tarsal bones. Further, carpal and tarsal bones are less likely to be influenced by the noise created from conflicting signals of genetics and lifestyle that obfuscates differentiation of ultimate and proximate causes of variation that plagues the long bones (Pearson 2000; Ruff \& Larsen 2014). Further, these dense and small bones tend to be among the better-preserved bones in archaeological contexts (Henderson 1987; Mann 1981) and, if daily activities are visible in these bones, we potentially capture data that might otherwise be lost in less well-preserved skeletons. At the very least, if they prove useful in identifying bone functional adaptation, they provide additional data for past activity reconstruction. 
100 We examined carpal and tarsal bones from the Florida Early Archaic Windover Site. The Early Archaic is

101

102

103

104

105

106

107

108

109

110

111

112

113

114

115

116

117

118

119

120

121

122

123

124

125

126

127

128

129

130

131

132

133

134

135

136

137

138

139

140

141

142

143

144

145

146

147

148

149

150 characterized by major climate change in North America and, along with it, a change in domestic economies. Warmer climate was driving big game north and broad-spectrum foraging was emerging as the primary subsistence economy, de-emphasizing the dietary contribution of males and increasing the contributions of females. The site consists entirely of the mortuary pond where mobile hunter-gatherers buried their dead (usually with grave goods, such as atlatl, stone tools). Due to the semi-tropical environment of Florida, seasonally occupied hunter-gatherer camps are not well-preserved and most of what we know of this period comes from mortuary ponds, rather than occupation sites. As one of the bestpreserved and largest collections, Windover remains provide tremendous insights into this period. We generated research questions based on ethnographic and archaeological data from other hunter-gatherer populations and modified them based on specific patterns identified at the Windover Site in other studies on other skeletal elements. As such, the next section takes each area of interest (e.g., mobility) and starts with general patterns in hunter-gatherer populations then narrows down to what we know about Windover. Our specific research questions are placed at the end of Bioarchaeological Context after presenting the material that aided in their generation.

\section{Mobility Activity}

\section{BIOARCHAEOLOGICAL CONTEXT}

General hunter-gatherer patterns. Hunter-gatherer mobility can be described as residential (moving camp to a new location as in seasonal occupation of resource rich areas) and logistical (individuals and/or smaller groups temporarily split from the main group for shorter foraging trips or longer hunting trips) (Binford 1980; Kelly 1983) — this is particularly true for mobile hunter-gatherers that specialize in terrestrial resources (Marlowe 2005; Panter-Brick 2002; Sahlins 1968). There is some evidence for sexbased variation in hunter-gatherer mobility; modern Hadza hunter-gatherer males engage in greater daily walking distances at faster speeds than females (Berbesque et al. 2016; Raichlen et al. 2017).

Distal limbs have been implicated to a greater degree than upper limbs in reflecting habitual activity due to the biomechanical forces arising from locomotive substrate (i.e., terrains on which activities are conducted), distances travelled in a day, and relative speed of locomotion (Berbesque et al. 2016; Bridges 1991; Bridges 1995; Carlson et al. 2007; Eshed et al. 2004; Lieverse et al. 2007; Malina \& Little 2008; Pearson 2000; Pontzer et al. 2014; Raichlen et al. 2017; Ruff 1987a; Ruff 2000; Shaw \& Stock 2009; Stock 2006; Venkataraman et al. 2013; Weiss 2012). Of interest to this study is how biomechanical stress from mobility and footedness might affect the tarsals - biomechanical stresses will cause the bone to functionally adapt to the stress through widening, as discussed previously (Garn 1972; Rauch 2005).

The ground reaction force generated by the bare (or minimally shod) foot contacting the ground is transmitted through the subtalar skeleton, with peak forces at heel-strike through the calcaneus and at heel-off through the metatarsophalangeal articulations (Trinkaus \& Shang 2008). Thus, during normal locomotion, the typical bipedal heel strike transmits body mass from the tibia to the rear foot (talus and calcaneus) to the ground (Nordin \& Frankel 2012) while the shock of impact is absorbed by the midfoot (navicular, cuboid, and cuneiform bones) (Nordin \& Frankel 2012). The calcaneus is most affected by the rear heel strike and calcaneal tuber length (a proxy for Achilles tendon moment arm length) is correlated with running economy (long calcaneal tuber = greater energy cost) (Raichlen et al. 2011) Most data from extant hunter-gatherers (Hatala et al. 2013; Pontzer et al. 2014) and barefoot populations suggest a rear heel strike (Fredericks et al. 2015) is preferred among experienced runners. Dorsal spurs on the calcaneus are linked to increased activity while plantar spurs are linked to standing, inactivity, and excess weight (Weiss 2012). The navicular is a keystone bone in the arches of the foot that is impinged during foot strike by the talus and other cuneiforms. Structurally linking the rear- and mid-foot, it bears the transmission force of weight during the push-off phase of locomotion and experiences highly localized stress in middle one-third of the bone, which makes it prone to fracture in highly athletic individuals (Coris \& Lombardo 2003; de Clercq et al. 2008; Khan et al. 1994; Shakked et al. 2017). Anatomically, 
151 the intermediate cuneiform articulates with the navicular proximally and second metatarsal distally. The

152

153

154

155

156

157

158

159

160

161

162

163

164

165

166

167

168

169

170

171

172

173

174

175

176

177

178

179

180

181

182

183

184

185

186

187

188

189

190

191

192

193

194

195

196

197

198

199

200

201 second metatarsal-intermediate cuneiform joint is a highly stable keystone joint with limited mobility. Injury to the joint occurs via direct force from load applied to the base of the foot or indirect forces from a longitudinal force applied to a plantarflexed foot (Liu et al. 1997; Rodgers 1988):1826, which is particularly pronounced in barefoot populations (Franklin et al. 2015; Fredericks et al. 2015; Hollander et al. 2017; Hollander et al. 2016; Pontzer et al. 2014).

While footedness in humans develops in late childhood (11-12 years old) with a right skew (Gabbard 1996; Gentry \& Gabbard 1995), its influence on walking gait is not significant and is unlikely to affect the musculoskeletal system in the absence of other evidence of lateralization (Zverev 2006). Thus, regions of the foot may be differentially shaped by daily logistical mobility that emphasizes either slow walking and stationary weight-bearing activity (such as might occur when foraging in a patch) or rapid locomotion such as brisk walking or running that requires greater shock absorption. And, if subsistence-based activities are assigned based on sex (Frayer 1980; Ruff 1987b), there may be sex-differences in how these regions of the feet vary. Ultimately, biomechanical stress will cause bone functional adaptation and increased width (Garn 1972; Rauch 2005).

Windover patterns. The Windover bog, used seasonally for burials, was strategically located between the Indian River coastal lagoon system and the St. John's River - an area rich in marine, fresh water, and terrestrial resources - which indicates that the population did not have to travel long distances between seasons (Adovasio et al. 2009) and did not fission into smaller groups between visits to the pond (Wentz 2006). Seasonal mobility is indicated by analysis of preserved stomach contents which were from plants and fruits maturing during July and October. In addition, growth ring data recovered from mortuary stakes indicated the wood was harvested in late summer/early fall (Doran \& Dickel 1988a). Ultimately, the residential mobility of the Windover population was limited to a constrained geographic area around the bog with most evidence pointing to emergence of sedentism (Wentz 2006).

\section{Domestic economies and Activity Reconstruction}

General hunter-gatherer patterns. Domestic economies include subsistence activities and tool manufacture (which supports subsistence activities). Subsistence covaries with biological factors (e.g., habitat, reproduction, health) and cultural factors (e.g., social organization, sedentism, mobility). A comprehensive analysis of 229 hunter-gatherer diets, eco-environmental data, and plant-to-animal dietary ratios found that most populations consume similar amounts of carbohydrates (30-35\% of the diet) except in more extreme environments (i.e., increases in desert and tropical grasslands and decreases in higher latitudes) (Hiatt 1978). Indeed, there is a strong clinal pattern of variation in male and female caloric contributions to diet. Subsistence contributions by sex are inversely correlated with effective temperature, a combined measure of the intensity and annual distribution of solar radiation (Bailey 1960; Binford 1980). Higher latitudes and colder climates rely more on male caloric contributions from big game hunting while temperate and tropical regions rely more heavily on female caloric contributions across the spectrum (e.g., small game, fishing, and plants) (Hiatt 1978). In general, males tend to increase foraging activities in more stable productive habitats (Marlowe 2007) and females tend to decrease labor in subsistence activities when males are hunting big game (focusing instead on activities like weaving and cordage) (Waguespack 2005).

Evidence for activity patterns is referred to as the 'holy grail' of bioarchaeology (Jurmain et al. 2012) due to the lack of written records in prehistory and the high amount of inferential work involved to reconstruct them. In modern populations, however, tarsal bones are heavily implicated in repeated and sustained physical activity (e.g., running, walking long distances on a daily basis) (Murray et al. 2006). Sustained daily physical activity is consistent with the lifestyle described in ethnographies of contemporary huntergatherer populations (Pontzer et al. 2015; Pontzer et al. 2014; Raichlen et al. 2011; Raichlen et al. 2017). Likewise, carpal bones are responsive to physical stressors and arthritis, among other bony changes, has 
202 been documented in modern populations and tied to repetitive tasks (e.g. painting, pipetting) (El-Helaly et

203

204

205

206

207

208

209

210

211

212

213

214

215

216

217

218

219

220

221

222

223

224

225

226

227

228

229

230

231

232

233

234

235

236

237

238

239

240

241

242

243

244

245

246

247

248

249

250

251

al. 2017; Heilskov-Hansen et al. 2016). To date, there are no studies documenting bony or arthritic changes in the wrist due to foraging behaviors, but generally plant acquisition is thought to be repetitive and likely to employ some of the postures implicated in bony changes in the wrist (e.g. picking) (Vignais et al. 2016).

Ethnographic data also indicate that other (non-foraging) domestic economies such as tool making, child care and carrying, butchering, food preparation, production of textiles, and carrying firewood and water create physical strain (Bentley 1985; Cowlishaw 1981; Hurtado et al. 1985; Sahlins 1968). Increased reliance on tools is linked to evolutionarily more gracile bodies (Trinkaus 1983) but tool manufacturing and use are detectable on the body through increased upper limb robusticity (Carlson et al. 2007) and lateralization, or side preference (Stock et al. 2013). Unimanual activities (e.g., spear use) leave a distinct mark of directional asymmetry in the upper limbs compared to bimanual activities such as grinding or rowing (Weiss 2009). Indeed, extant hunter-gatherers exhibit strong hand preference specifically when making and using tools (Cavanagh et al. 2016; Robira et al. 2018) which suggests a mosaic progression to the extreme lateralization we see in modern populations (Stock et al. 2013). And, there is evidence in the archaeological record of sidedness varying between the sexes (Bridges 1991; Bridges 1994). While domestic economies vary across groups, they tend to be sex-based and more frequently involve lateralized repetitive stress compared to subsistence and mobility (Weiss 2009). Thus, bioarchaeological evidence of subsistence activities and tool manufacture may be found in repetitive stress to the musculoskeletal system and result in lateralized MSM, DJD, and osteoarthritis of the limbs involved. Carrying loads may place additional weight-bearing biomechanical stress on the foot and the domestic economies may serve to differentiate the wrists. These biomechanical stresses should differentiate bones more heavily implicated in specific activities and further differentiate between those more heavily engaged in those activities from those minimally (or not all) engaged in those activities.

\section{Windover Patterns}

Subsistence economies. Paleodietary analysis from carbon and nitrogen bone-collagen values and archaeobotanical information suggest exploitation of riparian (river-based) resources rather than the more common Florida Archaic use of marine mammals or terrestrial fauna such as deer or rabbit (Tuross et al. 1994). Males and females did not have significantly different isotope values for major dietary components (Wentz 2006; Wentz et al. 2006). Based on ethnographic data, the resource rich environment fostered by a milder wetter climate suggests greater reliance on female caloric contributions to diet (Hiatt 1978) and this is supported by grave goods - both males and females were found with materials for hunting small mammals, reptiles, and fish (Hamlin 2001). There is evidence of some specialization by sex because only male graves contained atlatl components (typical of hunter-gatherers and male spear use (Kelly 1983)), spears, lithic projectiles, and hollow point awls (for making fishing nets) and only females and subadult graves contained direct evidence for food processing (e.g., butchered bone, mortar and pestle, containers) (Adovasio et al. 2001; Hamlin 2001).

Tool economies. Analysis of tools found amongst the grave goods suggests tool material choice (not type) was sex-based; females preferred shell and carapace, while males preferred antler bone (Adovasio et al. 2009; Hamlin 2001). Few tool types were exclusive to one sex which suggests few activities were specific to one sex (Hamlin 2001). Females also tended to have more decorative items (Hamlin 2001) and were found exclusively with materials for plant-based medicine (Adovasio et al. 2009; Hamlin 2001; Tuross et al. 1994). Interestingly, stone tools only play a cameo in the story of tools at Windover (Adovasio et al. 2009) while female goods (textiles, baskets, containers, medicines) have a starring role across the history of the pond. The absence of internment with stone tools suggests a cultural emphasis on the labor of women and products from both men and women in the domestic economy rather than an emphasis on male big-game hunting (Adovasio et al. 2009). This may be an outcome of climate change 
252

253

254

255

256

257

258

259

260

261

262

263

264

265

266

267

268

269

270

271

272

273

274

275

276

277

278

279

280

281

282

283

284

285

286

287

288

289

290

291

292

293

294

295

296

297

298

299

300

301

302
(Doran \& Dickel 1988b; Milanich 1994) rapidly altering domestic roles from the Paleoindian to the Early Archaic periods.

Activity Reconstruction. DJD at Windover has been analyzed in two separate studies (Smith 2008; Wentz 2010), each using different but standard published methods. Smith used Waldron's method(Smith 2008) based on bone eburnation (or polishing) (Waldron 1991; Waldron \& Rogers 1991) and other arthritic changes at the joint (e.g., lipping, porosity). Wentz (Wentz 2010) used the Western Hemisphere Health Index methods, a relative ordinal ranked scoring system in eight skeletal joints (Steckel \& Rose 2002). Both studies found high rates of DJD in males and females consistent with prehistoric huntergatherer lifestyles, but there were no statistically significant between-sex differences in DJD (Smith 2008; Wentz 2010). There were some sex-based trends that are relevant to the current study. First, DJD frequency in the cervical spine is particularly high in females and may be explained by food or palm leaf (for textile fibers) processing activities (Wentz 2010) or carrying heavy loads (Smith 2008) both of which are supported by grave good evidence (Adovasio et al. 2001; Adovasio et al. 2009; Hamlin 2001). Males exhibit greater DJD in the lumbar region which suggests they were carrying heavy loads (perhaps game or goods during seasonal camp relocation) or stressed from repetitive motions related to hide processing (Wentz 2010). Thus, both males and females may have been carrying heavy loads and both were engaging in similar or shared tasks (Smith 2008:45). Second, elbows were commonly affected which might be interpreted as male atlatl throwing but females exhibited more DJD in wrists, elbows and shoulders than males (Wentz 2010) which suggests a shared activity (Smith 2008). Wrists exhibited little evidence of DJD (3/97 left and right wrists affected) but females had more hand trauma (Wentz 2010) and males had a higher frequency of severe DJD in both hands (18\% of the sample) (Smith 2008). Again, similar or shared tasks are indicated. Third, there were some overall sex-based patterns in DJD with males exhibiting more knee and hip damage on the left and females exhibiting more severe change on the right (Smith 2008), which might suggest footedness and increased mobility in males with more shock to the feet. Both sexes (37\% of individuals) exhibited significant bilateral degeneration of talar-calcaneal articular facets (Smith 2008), which might reflect high mobility and weight-bearing activities (Weiss 2012), possibly running (Franklin et al. 2015; Fredericks et al. 2015; Hollander et al. 2017; Raichlen et al. 2011).

An examination of muscle insertion sites (Hagaman 2009) found low levels of habitual stress (indicative of stressful repetitive activity) but muscle insertion sites were fairly robust indicating generally high activity patterns. As with the DJD results, there is much overlap between the sexes in scores further supporting the notion that most activities were shared. The lack of asymmetry in MSM, particularly in males due to the use of the atlatl, suggests a lack of repetition in this activity or other activities which exert symmetrical force on the upper limbs and obscure the lateralization of spear-throwing - possibly kayaking (Hagaman 2009). But, the wrist is a complex system in which small changes in the anatomy of one bone be offset by changes in other aspects of the anatomy (Maki 2013:238). Analysis of fractures suggests interpersonal violence (affecting male crania and, less frequently, the post cranial skeleton) but the majority of trauma came from accidents with females slightly more affected than males (Smith 2003). Ribs (often on the right side) were the most fractured in both sexes with ulnar fractures in second place. The vertebra exhibit evidence of compression fractures (more frequent in females and equal to ulna fractures in incidence) consistent with falls when landing in an upright position or carrying heavy loads (Smith 2003). Overall, fracture patterns suggest accidents related to logistical mobility in the uneven intercoastal terrain and heavy underbrush along with heavy load carrying (Smith 2003).

\section{MATERIALS}

The Windover archaeological site (8BR46) is a National Historic Landmark dating to the Early Archaic Period (7500-5000 BCE) with calibrated radio-carbon dates from 9000 to $7929 \mathrm{BP}$. The site consists of a mortuary pond where seasonal mobile hunter-gatherers buried their dead. The Windover bog site 
303

304

305

306

307

308

309

310

311

312

313

314

315

316

317

318

319

320

321

322

323

324

325

326

327

328

329

330

331

332

333

334

335

336

337

338

339

340

341

342

343

344

345

346

347

348

349

350

351

352

353

$\left(5,400 \mathrm{~m}^{2}\right)$ is one of a number of Florida Archaic Period 'wet cemeteries' or mortuary pond archaeological sites with underwater burials in peat; others include Little Salt Spring (8SO18) (Clausen et al. 1979), Republic Grove (8HR4) (Wharton et al. 1981), and Bay West (8CR200) (Beriault et al. 1981 ). Little is known about this time period because skeletal remains in these sites are most often from a very small number of individuals, are often very fragmentary, and some sites were not excavated systematically (such as Little Salt Springs) (Wentz \& Gifford 2007). Further, the semi-tropical conditions of Florida are less than ideal preservation conditions, especially for temporary occupation sites that might consist of minimal non-organic materials.

In general, the North American Archaic Period (8000 to $1000 \mathrm{BC}$ ) is characterized by hunting-gathering subsistence economies with dietary staples including nuts, seeds, and shellfish (Milanich 1994). The Florida Archaic Period follows the same pattern (e.g., broad spectrum hunting, fishing, and plant gathering and use of freshwater resources) with increased exploitation of coastal shellfish and marine resources. The comparatively wetter climate (Halligan et al. 2016) created an abundance of resources and subsistence strategies were no longer dominated by big game. The broad spectrum foraging strategy that emerged is reflected in more complex tool kits (Doran \& Dickel 1988b; Milanich 1994). See Brown (1994), Klingle (2006), and Milanich (1994) (Milanich 1994) for overviews of Florida prehistory.

The Windover site was used as a mortuary pond for 5-6 short periods of activity, peaking at $7450 \mathrm{BP}$ (Doran \& Dickel 1988a; Doran \& Dickel 1988b). Burials furthest from the pond edge at time of excavation dated to the earliest period of mortuary pond use and those closest, more recent. Roughly 100 burials were undisturbed with fully articulated bones; ages ranged from infancy to over sixty-five, with $52 \%$ classified as subadults (Purdy 1991). Most individuals were buried within 24 to 48 hours after death (Doran 1992; Dickel 1988, Hauswirth 1991) in a flexed position, on the left side with heads oriented to the west, and pinned by sharpened stakes approximately $1 \mathrm{~m}$ below the surface of the peat (Hauswirth et al. 1994). The nearly neutral $\mathrm{pH}$ of the pond (6.1-6.9) created ideal conditions for preservation of both skeletal and soft tissues; allowing researchers to sequence DNA from preserved brain matter (Hauswirth et al. 1994), reconstruct diet from preserved stomach contents (Tuross et al. 1994), and study textile industries (Adovasio et al. 2001). The population exhibited predominantly good health and included individuals of extremely advanced age (50+) for hunter-gatherer groups which reflects local resource abundance (Klingle 2006) and medical practices (Adovasio et al. 2009; Hamlin 2001; Smith 2003; Tuross et al. 1994; Wentz 2006). Common to hunter-gatherer populations, adults of both sexes exhibited a high incidence of osteoarthritis (Smith 2008), frequent enamel defects (Berbesque \& Doran 2008; Berbesque \& Hoover 2018), and skeletal trauma (Smith 2003). Overall, female health was worse than male health (Wentz 2006; Wentz et al. 2006).

\section{Research Questions \\ Mobility}

1. Previous research indicates that male hunter-gatherers walk more and at greater speeds than females. Windover data suggest a shared labor load, reduced emphasis on big game hunting, and evidence for heavy load carrying in both sexes. Which model is reflected in bone functional adaptation? We might expect the shared load model at Windover to result in no significant between-sex differences in rear foot tarsal variables that reflect the ground force reaction during locomotion and midfoot tarsal variables that absorb shock during locomotion.

2. The asymmetrical DJD in lower limbs and fracture patterns reviewed previously suggest there Subsistence may be tarsal asymmetry. Is this evidenced by directional asymmetry in tarsal bones?

1. Previous research finds greater hand trauma and domestic economy production in females but greater DJD in males. Are there between-sex differences in carpal bones?

2. Based on findings of asymmetry in contemporary populations (hunter-gatherer and industrialized) engaged in repetitive manual tasks, we might expect prehistoric hunter-gatherers regularly 
354

355

356

357

358

359

360

361

362

363

364

365

366

367

368

369

370

371

372

373

374

375

376

377

378

379

380

381

382

383

384

385

386

387

388

389

390

391

392

393

394

395

396

397

398

399

400

401

402

403

404

engaged in repetitive manual tasks (food processing, tool production) to exhibit a similar pattern. Is there directional asymmetry in the carpal bones studied?

\section{METHODS}

Raw Data Collection and Variables. Carpal and tarsal bones with standard anatomical reference points intact were included only from adults who had well-defined features used in sex assessment (given the focus on sex-based morphological variation). Sex assessment was carried out by Doran and Dickel (Doran \& Dickel 1988a) using nonmetric pelvic and cranial traits and metric analysis of femoral and humeral head dimensions following standard osteological methods (Buikstra \& Ubelaker 1994). The final sample was 44 ( 27 males, 17 females) but sample size varies by measurement. All measurements were taken on right and left sides, when available for inclusion in the directional asymmetry analysis. Length and width of whole bones were measured in millimeters for four carpals (capitate, hamate, lunate and scaphoid) and four tarsals (calcaneus, intermediate cuneiform, navicular, talus). Length and width of talar (trochlea) and calcaneal (load arm) articular surfaces were also measured. See Table 1 for measurement details using standard anatomical landmarks.

Size Difference Data and Directional Asymmetry Analysis. Directional asymmetry is assessed by comparing side differences (here, selected right and left hand and foot bones). Confounding factors for directional asymmetry analysis are sexual dimorphism and trait size variation, discussed in-depth in asymmetry methodology papers that were applied to this analysis (Palmer 1994; Palmer \& Strobeck 1986; Palmer \& Strobeck 2003). Preliminary raw data inspection via scatterplots and outlier statistical tests (e.g., Grubb's statistic) were performed to eliminate confounding effects of outliers (data recording, trait size, anomalous individuals) (Palmer \& Strobeck 2003). Univariate analysis generated input for a mixed model ANOVA (sides x individuals) which was performed in the Fluctuating Asymmetry Calculations Worksheet (V.11) (Palmer 1994; Palmer \& Strobeck 1986; Palmer \& Strobeck 2003).

Bone Functional Adaptation, Index Data and Analysis. As discussed previously, bone functional adaptation in response to biomechanical forces can be assessed by bone width as a proxy for relative bone strength (Garn 1972; Rauch 2005). But, sexual dimorphism (Fairbairn 1997; Jungers 1984; Smith \& Cheverud 2002) and trait size variation (Huxley \& Tessier 1936; Lewontin 1966) confound analysis conducted on raw width measurements. For example, a comparison between the width of the intermediate cuneiform and the width of the talus simply demonstrates that the talus is a wider bone because it is a larger bone. Likewise, a comparison between male and female talus widths simply demonstrates that males tend to be larger than females. An approach using raw measurements does not further our understanding of meaningful trait differences beyond absolute size.

A common resolution to the effect from sexual dimorphism is to take a ratio of two variables, such as length and width (Fairbairn 1997; Huxley \& Tessier 1936; Jungers 1984; Jungers et al. 1995; Lewontin 1966; Mobb \& Wood 1977; Smith \& Cheverud 2002). We take length and width because width is an indicator of relative bone strength (Garn 1972; Rauch 2005) - and length and width are commonly taken, easily replicated measurements. As previously mentioned, resistance to bending force is related to bone diameter because apposition of new bone on periosteal surfaces (a functional adaptation to biomechanical stress) widens the bone (Macdonald et al. 2013). Thus, the ratio of length to width provides a useful index of relative bone strength and is a marker of biomechanical forces acting on bone functional adaptation from activity. An index of one describes a bone that has equal length and width (1:1). A ratio of greater than one describes a bone that is longer than it is wide and a ratio of less than one describes a bone that is wider than it is long. When comparing bones that have indices that lie exclusively either above or below the set point of one, the relative bone strength can be inferred by smaller numbers. For example, if all the bones are wider than they are long (a ratio value below 1), those with the smallest values are relatively wider than those with larger values (but, see below for interpreting logged values). 
The issue of trait size variation is common in asymmetry studies (Palmer 1994; Palmer \& Strobeck 1986; Palmer \& Strobeck 2003) and often resolved by scaling data to the natural log after taking the absolute value of the length to width index (Mobb \& Wood 1977; Palmer \& Strobeck 2003). The natural log creates a symmetric and homoscedastic dataset that retains the original linear scale of standard deviation to the mean (the spread or variation of the data) (Sokal \& Rohlf 1995). We applied this final transformation to our data and that resulted in a total of 10 index variables (capitate, hamate, lunate, scaphoid, calcaneus, calcaneus load arm, intermediate cuneiform, navicular, talus, talus trochlea tibia) to test bone functional adaptation analysis. We transformed left and right sides separately because each represents an individual measure of biomechanical stress. Equation 1 (Eq. 1) represents the full transformation of raw length and width variables to the final index that accounts for the confounding issues of sexual dimorphism and trait size. The index is derived from the natural $\log \left(\log _{\mathrm{n}}\right)$ of the absolute value of length-to-width ratio $(L: W)$ for each trait $(x)$

Eq. 1: $\log _{\mathrm{n}}|\mathrm{x}(\mathrm{L}: \mathrm{W})|$

An example of how this index mitigates the confounding effects of sex-based and trait-based size differences in bone metrics is seen in Figure 1 (and Supplementary Figures 1-9). The left panel of Figure 1 is a scatterplot of raw measurements for the navicular. The right panel of Figure 1 is a scatterplot of the index values. The distribution of raw data on the left reflects the absolute differences in body size (males larger than females) while the right panel reflects real differences once absolute size differences are eliminated by application of Equation 1. Our index values describe bones that are absolutely longer than they are wide excepting the calcaneus load arm which is wider (than it is long) and the lunate which is equal in length and width (14.43:14.90 or .99). See Table 2 for an average of ratio values using raw length and width measurements (L:W) and an average of index values using Equation 1. Table 2 demonstrates that the linear scale of the original data is retained and can be interpreted in a similar manner as before with the exception that values greater than zero are longer than they are wide (i.e., relatively long) and values less than zero are wider than they are long (i.e., relatively wide). To return to the earlier example, if all the bones are wider than they are long (a logged ratio value below 0 ), those with the smallest values (larger negative values) are relatively wider than those with larger values (closer to zero).

Tests for between-group differences using index variables characterized differences in relative width as an indication of biomechanical stress acting on the area of interest. The General Linear Model (GLM) was used to test for between-sex differences in tarsal and carpal variables. All results were evaluated relative to confidence intervals, power, and estimated effect size.

\section{RESULTS}

Outlier data identified by Grubb's statistic were examined relative to other measurements for the individual and were removed if inconsistent and not a result of data entry error (see notes tab in the raw data file). Five outliers were found to be due to data entry error and were corrected (see notes tab in the raw data file). All variables were normally distributed (Supplementary Table 1). Descriptive data for all variables by sex are found in Supplementary Table 2.

Are there between-sex differences in tarsal weight-bearing index values and tarsal shock-absorbing index values? As discussed in the introduction, body weight is born by the rear foot (talus and calcaneus) during heel strike (Nordin \& Frankel 2012; Trinkaus \& Shang 2008) and impact shock is absorbed by the midfoot (navicular, cuboid, and cuneiform bones) (Nordin \& Frankel 2012). We used a multivariate GLM to assess sex differences and test the hypothesis that Windover had a shared labor load that deviates from what might be expected in typical hunter-gatherers with a sex-based division of labor. Results of the multivariate GLM using index values (the index corrects for sex dimorphism and trait size variation) confirmed expectations: there were no significant between-sex differences in weight-bearing (Pillai's 
456 Trace $\mathrm{F}=1.522, \mathrm{df}=4, \mathrm{p}=0.205, \eta \mathrm{p}=0.132$; observed power $=0.437$ ) or shock-absorbing tarsals (Pillai's Trace $\mathrm{F}=2.599, \mathrm{df}=2, \mathrm{p}=0.084, \eta \mathrm{p}=0.093$; observed power $=0.495$ ). Both tests are underpowered with small effect sizes. The p-value for weight-bearing bones is high, which suggests minimal chance of Type II error. The p-value for shock-absorbing bones, however, is low which might indicate Type II error from the small sample size. Between-subjects tests for each index variable (Table 3, Figures 2 and 3, Supplementary Figures 1-5) indicate that the calcaneus exhibits a sex-based trend, but the p-value (0.021) is not significant after multiple-hypothesis test correction $(\alpha=0.0125)$.

Is there directional asymmetry that might indicate lateralization of the foot evidenced in tarsals as suggested by asymmetrical DJD in lower limbs and fracture patterns? The mixed-model results did not indicate significant between-side differences in raw tarsal measurement variables (length and width for four bones and length and width for two articular facets), which suggests there is no directional asymmetry or 'footedness' present (Supplementary Table 3).

Is there a between-sex difference in carpal bones based on previous research showing greater hand trauma and domestic economy production in females? Or, is the previous research showing greater DJD in male hands an equalizing effect on the skeletal embodiment of different activity patterns? The p-values for the results of a multivariate GLM on carpal index variables for between-sex differences were not significant (Pillai's Trace $\mathrm{F}=2.811, \mathrm{p}=0.059, \eta \mathrm{p}=0.0398$; observed power $=0.639$ ). The $\mathrm{p}$-value exceeds the set $\alpha$ level $(0.05)$ by a very narrow margin $(0.09)$ and the test was underpowered $(64 \%)$, both of which suggest possible Type II error due to insufficient sample size (the female sample was much smaller than the male sample) - an unfortunate problem common to many bioarchaeological studies. Between-subjects tests for

\section{DISCUSSION}

Archaeological data reconstructing the environment surrounding the mortuary pond suggest that the larger region was rich with riparian and terrestrial resources due to climate warming at the start of the Early Archaic. As megafauna distributions increased in latitude, Windover subsistence strategies progressively relied less on big-game hunting and more on broad spectrum foraging (Doran \& Dickel 1988a; Halligan et al. 2016). Grave good analysis and activity reconstructions suggest heavy overlap between the sexes in domestic economies rather than a strict sex-based division of labor (Hagaman 2009; Hamlin 2001; Smith 2008; Smith 2003; Wentz 2006).

\section{Tarsal Variation}

496

Based on previous analysis, we speculated whether the biomechanical stress of load carrying might influence bone functional adaptation in the tarsals. Typical hunter-gatherer males have faster walking speeds and tend to walk greater distances than females (Pontzer et al. 2014). If males were more specialized in hunting activities that required them to walk longer distances at faster speeds than females, we might expect relatively wider (i.e., stronger) weight-bearing bones in males (lower index values for talus and calcaneus variables) - this expectation is predicated on body weight being born by the rear foot (talus and calcaneus) (Nordin \& Frankel 2012; Trinkaus \& Shang 2008). We also might expect males to have greater impact shock from locomotion, which is absorbed by the midfoot (navicular, cuboid, and cuneiform bones) (Nordin \& Frankel 2012). The archaeological interpretation of the division of labor at 
505

506

507

508

509

510

511

512

513

514

515

516

517

518

519

520

521

522

523

524

525

526

527

528

529

530

531

532

533

534

535

536

537

538

539

540

541

542

543

544

545

546

547

548

549

550

551

552

553

554

555

Windover, while limited to grave goods, suggests a shared model of labor. If males are less specialized and share domestic economy tasks with females, we would expect no differences in the sexes and this is what we found. That said, both tests are underpowered and there may well be significant differences in the shock-absorbing bones that were not identified due to small sample sizes per variable. Still, the effect is very low (in this study), which suggests that any differences that might exist are not likely to have biological significance.

The calcaneus index values are the only ones that exhibit a clear sex-based trend (even if not significant after correction for multiple hypothesis testing). Recall that the bipedal heel strike during locomotion transmits body mass from the tibia to the rear foot (talus and calcaneus) to the ground (Nordin \& Frankel 2012). Extant hunter-gatherer Hadza tend to favor a midfoot strike (Pontzer et al. 2014) while the Daasanach pastorlists favor a rearfoot strike (Hatala et al. 2013), the latter of which significantly impacts the calcaneus more so than other bones and which increases dorsal spurs on the calcaneus (Weiss 2012). Calcaneal dorsal spurs are correlated with running economy (long calcaneal tuber $=$ greater energy cost) (Raichlen et al. 2011) - this has been noted in endurance runners in Kenya but who appear to favor a forefoot strike(Lieberman et al. 2015). Because the Windover population was experiencing a comparatively wetter climate than in previous archaeological periods (Halligan et al. 2016), big game was harder to find. We know that the population had an abundance of local resources and emphasized broad spectrum foraging over big-game hunting (Doran \& Dickel 1988b; Milanich 1994). Male burials, however, sometimes are associated with atlatls which suggests some big game hunting and might explain why males have relatively longer calcaneus bones than females (higher index values, closer to zero, are interpreted as relatively longer and lower index values, larger negative numbers, are interpreted as relatively wider). While some research argues that barefootedness causes wider feet (Lieberman 2013), the situation is more complex. Clinical evidence of the effect on the foot due to barefoot walking and running during growth and development suggests that while the forefoot does widen (Franklin et al. 2015), the overall length is increased at the expense of width even when controlling for potentially confounding effects of demographic and developmental variation in activity and body weight (Hollander et al. 2017). A large cohort ( $\mathrm{n}=520)$ of children aged 6-18 in South Africa (habitually barefoot, even in school) and Germany showed that the wider foot cedes to a longer foot in the South African barefoot cohort. Variation in findings across published may be related to factors such as the confounding factors influencing adult foot morphology and, in the one other study conducted on habitually barefoot children (D’AoÛt et al. 2009), factors such as BMI and ligament tensility (Hollander et al. 2017). The story of foot morphology and barefootedness is not yet complete.

\section{Foot Lateralization}

Despite evidence suggesting footedness would not be visible in the archaeological record (Zverev 2006), bioarchaeological evidence suggested there might be - namely, lateralization in the lower limbs might have resulted in lateralization of tarsal bones with the dominant foot having larger mid foot widths (due to biomechanical pressure to strengthen the bone during impact) or rear foot widths (due to biomechanical pressure to strengthen the bone during weight-bearing). Specifically, males had greater DJD on both knees and the left talus and calcaneus (Smith 2008:47). These lateral patterns did not translate to differences in the tarsals bones in this population. As previously discussed, footedness in humans develops in late childhood (11-12 years old) with a right skew (Gabbard 1996; Gentry \& Gabbard 1995) but its influence on walking gait is not significant and not likely to affect the musculoskeletal system in the absence of other evidence of lateralization (Zverev 2006). A future study might confirm this by examining bone functional adaptation in response to foot preference in populations with known physical activity patterns that evidence clear lateralization. Further, the hallux has been identified as a potentially significant bone that might be examined in bioarchaeological contexts due to its involvement in the extreme plantarflexion associated with barefoot locomotion (Franklin et al. 2015).

\section{Carpal Variation}


556

557

558

559

560

561

562

563

564

565

566

567

568

569

570

571

572

573

574

575

576

577

578

579

580

581

582

583

584

585

586

587

588

589

590

591

592

593

594

595

596

597

598

599

600

601

602

603

604

605

606

We postulated we would find between-sex differences in carpal bones due to increased hand trauma (Wentz 2010) and cervical vertebra DJD in females (possibly linked to food and textile processing activities) (Adovasio et al. 2001; Adovasio et al. 2009; Wentz 2010) compared to males who had a higher frequency of severe DJD in both hands (18\% of the sample) (Smith 2008). The multivariate test conducted on the index variables for the four carpal bones did not result in a significant finding of difference between males and females but, as noted in Results, the test was underpowered and the p-value was only slightly higher than the significance threshold. Thus, a Type II error may have occurred. The female carpal sample is smaller than the male carpal sample and there is no way to predict what the differences might actually be. The between-subjects tests did not indicate any individual variable was significantly different between the sexes but these were underpowered due to small sample size, particularly for females and the hamate index. Given that the female sample is much smaller than the male sample, we cannot comfortably make any conclusions relative to the research question. We can, however, suggest that there is very small (if any) effect size from activity marking on the bones due to biomechanical stress (in this study). And we note that a lack of difference circumstantially supports prior analysis suggesting heavy overlap between the sexes in labor as evidenced by male graves containing tools for domestic labor (Hagaman 2009; Hamlin 2001; Smith 2008; Smith 2003; Wentz 2006)

There were some interesting trends worth noting even if they are not part of statistical hypothesis testing. First, female carpals (excepting the scaphoid) exhibit a greater range of index values than males (Table 4, Supplementary Table 2). Females engage in broader non-diet activity (e.g., weaving, cordage) when male contributions to diet are larger (Waguespack 2005). Given that the Early Archaic is characterized by rapid change from big game hunting to broad spectrum foraging (Doran \& Dickel 1988a; Halligan et al. 2016; Milanich 1994) and given that Windover females are engaging in both subsistence and non-subsistence domestic activities (Hagaman 2009; Hamlin 2001; Wentz 2010), perhaps our data reflect this transition and greater variety in female workload. First, female specific activities include health care as evidenced by grave goods for medicine preparation (Hamlin 2001; Wentz \& Gifford 2007) and the Windover population experienced a variety of ailments (e.g., post-fracture bone alignment, surviving childhood stressors) (Wentz 2006; Wentz 2010; Wentz et al. 2006). Second, the sex-based preference for tool materials suggests a gendered ideology surrounding tasks (Hamlin 2001). Finally, a between-sex health comparison found females had poorer health, which might be attributable to greater life stress from a heavier workload (Wentz et al. 2006). Thus, while we cannot conclude there are differences in biomechanical stress on carpal bones, we can suggest there may be evidence of females engaging in a wider variety of tasks. Ultimately and partly as a result of the very small effect size, the carpals do not appear to be useful (at least in this study) in identifying between-sex differences in biomechanical stressors from activity. But, perhaps the results reflect the 'shared-load' model put forward for Windover division of labor.

\section{Hand Lateralization}

Our final area of inquiry was whether there was any evidence for lateralization in the carpal bones; this was based on previous research that suggested that hunter-gatherers exhibit strong handedness when engaged in complex tasks (Cavanagh et al. 2016; Robira et al. 2018; Stock et al. 2013). The complex tool kit at Windover would have provided an avenue for handedness to be archaeologically visible, but neither male nor female carpal bones exhibited significant directional asymmetry that would suggest lateralization. We might have expected some lateralization in males if the carpals were implicated in spear-throwing and males were engaged in heavy hunting activities but the Windover archaeological record does not suggest this was the case. Further, the bioarchaeological record shows that DJD and MSM patterns were shared between the sexes which suggests that males were not likely regularly engaged in hunting or the markers of habitual spear-throwing were offset by changes in other aspects of wrist anatomy (Maki 2013):238. A previous study on a population with clear handedness identified only two bones exhibiting directional asymmetry, the lunate and trapezium (Reina et al. 2017) which suggests handedness is not likely to be archaeologically visible. 
607

608

609

610

611

612

613

614

615

616

617

618

619

620

621

622

623

624

625

626

627

628

629

630

631

632

633

634

635

636

637

638

639

640

641

642

643

644

645

646

647

648

649

650

651

652

653

654

655

656

657

\section{CONCLUSION}

This paper explores the biomechanical stresses acting on bone functional morphology in carpal and tarsal bones as a novel method of identifying the embodiment of logistical mobility and domestic economies (subsistence and tool manufacture). We identified key characteristics of hunter-gatherer mobility and domestic economies that might leave their mark on the bone. And, we used the wealth of data published on the Windover population from other bioarchaeological and archaeological studies to guide our expectations of what we might find in the carpals and tarsals.

We were particularly interested in the archaeological visibility of lateralization. Previous studies on the subject of lateralization in humans (past and modern) are not entirely on agreement on what expectations might be. Modern populations exhibit footedness (Gabbard 1996; Gentry \& Gabbard 1995) and handedness (Stock et al. 2013) but extant hunter-gatherers only exhibit handedness during activities involving complex tasks (Cavanagh et al. 2016; Hurtado et al. 1985; Robira et al. 2018) and footedness has not been studied. Even though hunter-gatherers have been studied in terms of gait and locomotion (Fredericks et al. 2015; Hatala et al. 2013 Pontzer, 2014 \#5479; Lieberman et al. 2010; Niemitz 2010; Pontzer et al. 2014), studies on modern populations indicate that the influence of walking gait on footedness is not significant (Zverev 2006). We used raw measurements of length and width in carpal and tarsal bones to identify any directional asymmetry in the sample (as a proxy for lateralization). There was no evidence of directional asymmetry in the sample and our findings seem in line with the general understanding that hunter-gatherers do not exhibit hand preference enough for handedness to be archaeological visible. Further, hunter-gatherers, even if they exhibit foot preference (as suggested by lateralization of musculoskeletal markers), foot preference has little impact on the bones.

We were also interested in whether there were sex-based differences in weight-bearing regions of rear foot (talus and calcaneus) and shock-absorbing regions of the mid foot (intermediate cuneiform and navicular). We used an index variable for four tarsal bones and two tarsal articular surfaces to examine sex-based differences in mobility. While most hunter-gatherer populations might be expected to vary between the sexes based on different mobility patterns, Windover hunter-gatherers were not expected to because the archaeological evidence for labor suggests a shared load. We found no sex-based differences in either area of the foot which may support the shared load model given that male bones are not showing a significant bone functional adaptation to greater locomotory biomechanical stress (walking longer distances at greater speeds). But, the tests were underpowered due to small sample sizes and female samples were smaller than male samples. Still, the effect size was so small that any significant differences would not likely have biological significance. Male calcaneus index values are higher (closer to zero on the logged scale) which suggests they are relatively longer than female index values. The result is not statistically significant after correcting for multiple hypothesis testing but it might signify some remaining male hunting activity, or at the very least, some minimal between-sex differences in mobility (Franklin et al. 2015; Fredericks et al. 2015; Hollander et al. 2017).

Finally, we were interested in whether the carpal bones reflected the shared load model (Hamlin 2001) or if it reflected a partially shared load with greater female burden (Wentz 2006; Wentz 2010). We used an index variable for four carpal bones to examine differences in activity (shared workload or sex-based division of labor) (Cavanagh et al. 2016; Robira et al. 2018). Again, the tests were underpowered due to small sample sizes and female samples were smaller than male samples. The female range of index values is greater than the male and we suggest that perhaps females were engaging in a wider variety of tasks than males; there is some bioarchaeological evidence to support this postulation in the model for partially shared (male and female) tasks and heavier female workloads (Wentz 2006; Wentz 2010). Ultimately, we note that (in our sample at least), the effect size of activity pattern in differentiating the sexes is too small to be captured without a sufficiently large sample size. If this is generally true (i.e., the same pattern is

Peer] reviewing PDF | (2018:03:26634:2:0:NEW 3 Aug 2018) 
658

659

660

661

662

663

664

665

666

667

668

669

670

671

672

673

674

675

676

677

678

679

680

681

682

683

684

685

686

687

688

689

690

691

692

693

694

695

696

697

698

found in other collections), carpals are not a useful proxy for sex-based activity reconstruction in the absence of other traditional indicators.

While we cannot infer too deeply from the site because it is a mortuary pond and only reflects internment ritual, we can argue that our findings muddy the water in terms of the shared load model. Males and females are engaged in similar mobility patterns that emphasize weight-bearing rather than shockabsorbing activity. But, there is some evidence for sex-based differences in mobility - males are potentially still ranging further afield than females in pursuit of increasingly rare big game or simply have different locomotive patterns than females. While there are no sex-based differences in carpal bones, greater variation in female index values suggest that females may have been more specialized to specific tasks, or some engaged in female specific activities (as suggested by previous assessments of the high value placed on female labor at Windover) (Adovasio et al. 2009). But, if our findings are typical of how bone is marked by activity, the effect size of sex-based difference is too small to be of great use in interpreting activity patterns at archaeological sites. Finally, we can conclude that lateralization in the wrist and foot is not archaeologically visible in this population.

\section{ACKNOWLEDGEMENTS}

We wish to acknowledge Dr. Frank L. Williams (Georgia State University) for suggesting the frame of the study and Dr. Lia Betti (University of Roehampton) for reading an earlier version of this manuscript. We also thank Professor Glen Doran for access to the collection and his mentorship and support throughout our careers.

\section{REFERENCES}

Adovasio JM, Andrews RL, Hyland DC, and Illingworth JS. 2001. Perishable industries from the Windover Bog: An unexpected window into the Florida Archaic. North American Archaeologist 22:1-90. https://doi.org/10.2190/BX11-VDQY-LG5N-P94F

Adovasio JM, Soffer O, and Page J. 2009. The Invisible Sex: Uncovering the True Roles of Women in Prehistory. New York City: Harper-Collins e-books.

Bailey H. 1960. A method of determining warmth and temperateness of climate. Geografiska Annaler 43:1-16.

Bentley GR. 1985. Hunter-Gatherer Energetics and Fertility: A Reassessment of the !kung San. Human Ecology 13:79-109.

Berbesque JC, and Doran GH. 2008. Brief communication: physiological stress in the Florida Archaic-enamel hypoplasia and patterns of developmental insult in early North American hunter-gatherers. American Journal of Physical Anthropology 136:351-356. 10.1002/ajpa.20816

Berbesque JC, and Hoover KC. 2018. Frequency and developmental timing of linear enamel hypoplasia defects in Early Archaic Texan hunter-gatherers. PeerJ 6:e4367.

$$
10.7717 / \text { peerj.4367 }
$$


699

700

701

702

703

704

705

706

707

708

709

710

711

712

713

714

715

716

717

718

719

720

721

722

723

724

725

726

727

728

729

730

731

732

Berbesque JC, Marlowe FW, Pawn I, Thompson P, Johnson G, and Mabulla A. 2012. Sex differences in Hadza hunter-gatherer dental wear: A preliminary report. . Human Nature 23:270-282. 10.1007/s12110-012-9145-9

Berbesque JC, Wood BM, Crittenden AN, Mabulla A, and Marlowe FW. 2016. Eat first, share later: Hadza hunter-gatherer men consume more while foraging than in central places. Evolution and Human Behavior 37:281-286. https://doi.org/10.1016/j.evolhumbehav.2016.01.003

Beriault JG, Carr RS, Stipp JJ, Johnson R, and Meeder J. 1981 The Archaeological Salvage of the Bay West Site, Collier County, Florida. The Florida Anthropologist 34:39-58.

Binford LR. 1980. Willow Smoke and Dogs' Tails: Hunter-Gatherer Settlement Systems and Archaeological Site Formation. American Antiquity 45:4-20. 10.2307/279653

Bostanci E. 1962. A Biometrical and Morphological Study of the Astragalus and Calcaneus of the Roman People of Gordium in Anatolia: An Introduction to the Evolution of the Human Foot. Ankara: Turk Tarih Kurumu Basimevi.

Bridges PS. 1989. Changes in activities with the shift to agriculture in the Southeastern United States. Current Anthropology 30:385-394.

Bridges PS. 1991. Degenerative joint disease in hunter-gatherers and agriculturalists from the Southeastern United States. American Journal of Physical Anthropology 85:379-391. 10.1002/ajpa.1330850403

Bridges PS. 1994. Vertebral arthritis and physical activities in the prehistoric southeastern United States. American Journal of Physical Anthropology 93:83-93.

Bridges PS. 1995. Skeletal biology and behavior in ancient humans. Evolutionary Anthropology: Issues, News, and Reviews 4:112-120. 10.1002/evan.1360040403

Brown RC. 1994. Florida's First People: 12,000 Years of Human History. Sarasota, Florida: Pineapple Press.

Buikstra JE, and Ubelaker DH. 1994. Standards for Data Collection from Human Skeletal Remains: Proceedings of a Seminar at the Field Museum of Natural History. Fayetteville: Arkansas Archeological Survey.

Bunning P. 1964. Some observations on the West African calcaneus and the associated talocalceaneal interosseous ligamentous apparatus. American Journal of Physical Anthropology 37:373-388.

Carlson KJ, Grine FE, and Pearson OM. 2007. Robusticity and sexual dimorphism in the postcranium of modern hunter-gatherers from Australia. American Journal of Physical Anthropology 134:9-23. 10.1002/ajpa.20617 
733 Cavanagh T, Berbesque JC, Wood B, and Marlowe F. 2016. Hadza handedness: Lateralized behaviors in a contemporary hunter-gatherer population. Evolution and Human Behavior 37:202-209. http://dx.doi.org/10.1016/j.evolhumbehav.2015.11.002

Clausen CJ, Cohen AD, Emiliani C, Holman JA, and Stipp JJ. 1979. Little Salt Spring, Florida: A unique underwater site. Science 203:609-614. 10.1126/science.203.4381.609

Coris EE, and Lombardo JA. 2003. Tarsal navicular stress fractures. American Family Physician 67:85-90.

Cowlishaw G. 1981. The determinants of fertility among Australian Aborigines. Mankind 13:3755.

742

743

D’AoÛt K, Pataky TC, De Clercq D, and Aerts P. 2009. The effects of habitual footwear use: foot shape and function in native barefoot walkers. Footwear Science 1:81-94. $10.1080 / 19424280903386411$

Davies CM, Hackman L, and Black SM. 2014. The foot in forensic human identification - A review. The Foot 24:31-36. https://doi.org/10.1016/j.foot.2013.12.001

747

de Clercq PF, Bevernage BD, and Leemrijse T. 2008. Stress fracture of the navicular bone. Acta Orthopaedica Belgica 74:725-734.

Doran G, and Dickel D. 1988a. Multidisciplinary investigations at the Windover Site. In: Purdy B, ed. Wet Site Archaeology. Caldwell: Telford Press.

Doran GH, and Dickel DN. 1988b. Radiometric chronology at the Archaic Windover Site. Florida Anthropologist 41:365-380.

El-Helaly M, Balkhy HH, and Vallenius L. 2017. Carpal tunnel syndrome among laboratory technicians in relation to personal and ergonomic factors at work. Journal of Occupational Health 59:513-520.

Eshed V, Gopher A, Galili E, and Hershkovitz I. 2004. Musculoskeletal stress markers in Natufian hunter-gatherers and Neolithic farmers in the Levant: The upper limb. American Journal of Physical Anthropology 123:303-315. 10.1002/ajpa.10312

Estalrrich A, and Rosas A. 2015. Division of labor by sex and age in Neandertals: an approach through the study of activity-related dental wear. Journal of Human Evolution 80:51-63.

Fairbairn DJ. 1997. Allometry for Sexual Size Dimorphism: Pattern and Process in the Coevolution of Body Size in Males and Females. Annual Review of Ecology and Systematics 28:659-687. 10.1146/annurev.ecolsys.28.1.659

Franklin S, Grey MJ, Heneghan N, Bowen L, and Li F-X. 2015. Barefoot vs common footwear: 
767 Frayer DW. 1980. Sexual dimorphism and cultural evolution in the Late Pleistocene and

768 Holocene of Europe. Journal of Human Evolution 9:399-415. https://doi.org/10.1016/0047-

769 2484(80)90050-0

770

771

772

773

774

775

776

777

778

779

780

781

782

783

784

785

786

787

788

789

790

791

792

793

794

795

796

797

798

799

800
Frayer DW, and Wolpoff MH. 1985. Sexual Dimorphism. Annual Review of Anthropology 14:429-473. 10.1146/annurev.an.14.100185.002241

Fredericks W, Swank S, Teisberg M, Hampton B, Ridpath L, and Hanna JB. 2015. Lower Extremity Biomechanical Relationships with Different Speeds in Traditional, Minimalist, and Barefoot Footwear. Journal of Sports Science \& Medicine 14:276-283.

Gabbard C. 1996. Foot Laterality in Children, Adolescents, and Adults. Laterality: Asymmetries of Body, Brain and Cognition 1:199-206. 10.1080/713754236

Garn SM. 1972. The course of bone gain and the phases of bone loss. Orthopedic Clinics of North America 3:503-520.

Gentry V, and Gabbard C. 1995. Foot-Preference Behavior: A Developmental Perspective. The Journal of General Psychology 122:37-45. 10.1080/00221309.1995.9921220

Gualdi-Russo E. 2007. Sex determination from the talus and calcaneus measurements. Forensic Science International 171:151-156. https://doi.org/10.1016/j.forsciint.2006.10.014

Hagaman K. 2009. Activity-Induced Musculoskeletal Stress Marker Analysis of the Windover Population. MA. The Florida State University.

Halligan JJ, Waters MR, Perrotti A, Owens IJ, Feinberg JM, Bourne MD, Fenerty B, Winsborough B, Carlson D, Fisher DC, Stafford TW, and Dunbar JS. 2016. Pre-Clovis occupation 14,550 years ago at the Page-Ladson site, Florida, and the peopling of the Americas. Science Advances 2. 10.1126/sciadv.1600375

Hamlin C. 2001. Sharing the load: Gender and task division at the Windover Site. In: Arnold B, and Wicker NL, eds. Gender and the Archaeology of Death. AltaMira Press: Lanham, Maryland.

Harris SM, and Case DT. 2012. Sexual Dimorphism in the Tarsal Bones: Implications for Sex Determination. Journal of Forensic Sciences 57:295-305. 10.1111/j.1556-4029.2011.02004.x

Hatala KG, Dingwall HL, Wunderlich RE, and Richmond BG. 2013. Variation in Foot Strike Patterns during Running among Habitually Barefoot Populations. PloS One 8:e52548. 10.1371/journal.pone.0052548

Hauswirth WW, Dickel CD, and Lawlor DA. 1994. DNA analysis of the Windover population. In: Herrmann B, and Hummel S, eds. Ancient DNA: Recovery and Analysis of Genetic Material from Paleontological, Archaeological, Museum, Medical, and Forensic Specimens: Springer, 104-121. 
801 Heilskov-Hansen T, Mikkelsen S, Svendsen SW, Thygesen LC, Hansson GÅ, and Thomsen JF.

802 2016. Exposure-response relationships between movements and postures of the wrist and 803 carpal tunnel syndrome among male and female house painters: a retrospective cohort study. 804 Occupational and Environmental Medicine 73:401-408. http://dx.doi.org/10.1136/oemed$805 \quad 2015-103298$

806

Henderson J. 1987. Factors determining the state of preservation of human remains. In: Boddington A, Garland A, and Janaway R, eds. Death, Decay, and Reconstruction: Approaches to Archaeology and Forensic Sciences. Manchester, UK: Manchester University Press, 43-54.

Hiatt B. 1978. Woman the gatherer. In: Gale F, ed. Woman's Role in an Aboriginal Society. Canberra: Australian Institute of Aboriginal Studies, 4-15.

Hollander K, de Villiers JE, Sehner S, Wegscheider K, Braumann K-M, Venter R, and Zech A. 2017. Growing-up (habitually) barefoot influences the development of foot and arch morphology in children and adolescents. Scientific Reports 7:8079. 10.1038/s41598-01707868-4

Hollander K, van der Zwaard BC, de Villiers JE, Braumann K-M, Venter R, and Zech A. 2016. The effects of being habitually barefoot on foot mechanics and motor performance in children and adolescents aged 6-18 years: study protocol for a multicenter cross-sectional study (Barefoot LIFE project). Journal of Foot and Ankle Research 9:36. 10.1186/s13047-0160166-1

Hoover K. 1997. Carpals and Tarsals: Discriminant Functions for the Estimation of Sex Master of Arts. The Florida State University.

Hurtado A, Hawkes K, Hill K, and Kaplan H. 1985. Female subsistence strategies among Ache hunter-gatherers of Eastern Paraguay. Human Ecology 13:1-28.

Huxley JS, and Tessier G. 1936. Terminology of relative growth. Nature Biotechnology 137:780781.

Introna F, Jr., Di Vella G, Campobasso CP, and Dragone M. 1997. Sex determination by discriminant analysis of calcanei measurements. Journal of Forensic Sciences 42:725-728.

Jungers WL. 1984. Aspects of size and scaling in primate biology with special reference to the locomotor skeleton. American Journal of Physical Anthropology 27:73-97. 10.1002/ajpa.1330270505

Jungers WL, Falsetti AB, and Wall CE. 1995. Shape, relative size, and size-adjustments in morphometrics. Yearbook of Physical Anthropology 38:137-161.

Jurmain R, Alves CF, Henderson C, and Villotte S. 2012. Bioarchaeology's holy grail: the reconstruction of activity. In: Grauer AL, ed. A Companion to Paleopathology. Crichester, West Sussex: Wiley-Blackwell, 531-552. 
837 Kelly RL. 1983. Hunter-gatherer mobility strategies. Journal of Anthropological Research

838 39:277-306. 10.1086/jar.39.3.3629672

839 Khan KM, Brukner PD, Kearney C, Fuller PJ, Bradshaw CJ, and Kiss ZS. 1994. Tarsal navicular 840 stress fracture in athletes. Sports Medicine 17:65-76.

841 Kidd RS, and Oxnard CE. 2002. Patterns of morphological discrimination in selected human

842

843

844

845 tarsal elements. American Journal of Physical Anthropology 117:169-181. 10.1002/ajpa.20017

Klingle D. 2006. Burial in Florida: Culture, Ritual, Health, and Status: The Archaic to Seminole Periods MA. The Florida State University.

Lewontin RC. 1966. On the measurement of relative variability. Systematic Zoology 15:141-142.

847

848

Lieberman D. 2013. The Story of the Human Body: Evolution, Health, and Disease. New York: Vintage.

849

Lieberman DE, Castillo ER, Otarola-Castillo E, Sang MK, Sigei TK, Ojiambo R, Okutoyi P, and Pitsiladis Y. 2015. Variation in Foot Strike Patterns among Habitually Barefoot and Shod

851

852

853

854

855

856

857

858

859

860

861

862

863

864

865

866

867

868

869

870

Lieberman DE, Venkadesan M, Werbel WA, Daoud AI, D’Andrea S, Davis IS, Mang'Eni RO, and Pitsiladis Y. 2010. Foot strike patterns and collision forces in habitually barefoot versus shod runners. Nature 463:531. 10.1038/nature08723

https://www.nature.com/articles/nature08723\#supplementary-information

Lieverse AR, Weber AW, Bazaliiskiy VI, Goriunova OI, and Savel'ev NA. 2007. Osteoarthritis in Siberia's Cis-Baikal: Skeletal indicators of hunter-gatherer adaptation and cultural change. American Journal of Physical Anthropology 132:1-16. 10.1002/ajpa.20479

Liu GT, Lavery LA, Schenck RC, Lanctot DR, Zhu CF, and Athanasiou KA. 1997. Human articular cartilage biomechanics of the second metatarsal intermediate cuneiform joint. The Journal of Foot and Ankle Surgery 36:367-374. https://doi.org/10.1016/S10672516(97)80039-7

Macdonald HM, Hoy CL, and McKay HA. 2013. Chapter 42 - Bone Acquisition in Adolescence A2 - Marcus, Robert. In: Feldman D, Dempster DW, Luckey M, and Cauley JA, eds. Osteoporosis (Fourth Edition). San Diego: Academic Press, 1017-1036.

Maki JM. 2013. The Biomechanics of Spear Throwing: An Analysis of the Effects of Anatomical Variation on Throwing Performance, with Implications for the Fossil Record $\mathrm{PhD}$. Washington University in St. Louis.

Malina RM, and Little BB. 2008. Physical activity: The present in the context of the past. American Journal of Human Biology 20:373-391. 10.1002/ajhb.20772 
871 Mann D. 1981. Functional Information in Individual Anterior Tarsal Bones of Anthropoids M.A. 872 University of Illinois.

873 Marlowe FW. 2005. Hunter-gatherers and human evolution. Evolutionary Anthropology 14:5487467.

875 Marlowe FW. 2007. Hunting and gathering: The human sexual division of foraging labor. Cross$876 \quad$ Cultural Research 41:170-195.

877 Mastrangelo P, De Luca S, and Sanchez-Mejorada G. 2011a. Sex assessment from carpals bones: 878 Discriminant function analysis in a contemporary Mexican sample. Forensic Science 879 International 209:196.e191-196.e115.

Mastrangelo P, Luca S, Alemán I, and Botella M. 2011b. Sex assessment from the carpals bones: Discriminant function analysis in a 20th century Spanish sample. Forensic Science

883 International 206:216.e211-216.e210.

Milanich JT. 1994. Archaeology of Precolumbian Florida. Gainesville, Florida: The University Press of Florida.

Mobb GE, and Wood BA. 1977. Allometry and sexual dimorphism in the primate innominate

Murray SR, Reeder MT, Udermann BE, and Pettitt RW. 2006. High-risk stress fractures. Comprehensive Therapy 21:20-25.

Niemitz C. 2010. The evolution of the upright posture and gait - a review and a new synthesis. Die Naturwissenschaften 97:241-263. 10.1007/s00114-009-0637-3

Nordin M, and Frankel VH. 2012. Basic Biomechanics of the Musculoskeletal System.

Palmer AR. 1994. Fluctuating Asymmetry Analyses: A Primer. In: Markow TA, ed. Developmental Instability: Its Origins and Evolutionary Implications. Dordrecht,

Palmer AR, and Strobeck C. 1986. Fluctuating asymmetry: measurement, analysis, patterns. Annual Review of Ecology and Systematics 17:391-421.

Palmer AR, and Strobeck C. 2003. Fluctuating asymmetry analysis revisited. In: Polak M, ed. Developmental Instability (DI): Causes and Consequences. Oxford: Oxford University Press, 279-319.

901 Panter-Brick C. 2002. Sexual division of labor: energetic and evolutionary scenarios. American 902 Journal of Human Biology 14:627-640. 
903 Pearson Osbjorn M. 2000. Activity, Climate, and Postcranial Robusticity: Implications for 904 Modern Human Origins and Scenarios of Adaptive Change. Current Anthropology 41:569$905 \quad 607.10 .1086 / 317382$

906

907

908

909

910

911

912

913

914

915

916

917

918

919

920

921

922

923

924

925

926

927

928

929

930

931

932

933

934

935

936

Pontzer H, Raichlen DA, Wood BM, Emery Thompson M, Racette SB, Mabulla AZP, and Marlowe FW. 2015. Energy expenditure and activity among Hadza hunter-gatherers. American Journal of Human Biology 27:628-637. 10.1002/ajhb.22711

Pontzer H, Suchman K, Raichlen DA, Wood BM, Mabulla AZP, and Marlowe FW. 2014. Foot strike patterns and hind limb joint angles during running in Hadza hunter-gatherers. Journal of Sport and Health Science 3:95-101. https://doi.org/10.1016/j.jshs.2014.03.010

Purdy B. 1991. The Art and Archaeology of Florida's Wetlands. Boca Raton: CRC Press.

Raichlen DA, Armstrong H, and Lieberman DE. 2011. Calcaneus length determines running economy: Implications for endurance running performance in modern humans and Neandertals. Journal of Human Evolution 60:299-308.

https://doi.org/10.1016/j.jhevol.2010.11.002

Raichlen DA, Pontzer H, Harris JA, Mabulla AZP, Marlowe FW, Josh Snodgrass J, Eick G, Colette Berbesque J, Sancilio A, and Wood BM. 2017. Physical activity patterns and biomarkers of cardiovascular disease risk in hunter-gatherers. American Journal of Human Biology 29:e22919-n/a. 10.1002/ajhb.22919

Rauch F. 2005. Bone growth in length and width: the yin and yang of bone stability 194-201. Journal of Musculoskeletal \& Neuronal Interactions 5:194-201.

Reina N, Cavaignac E, Trousdale WH, Laffosse JM, and Braga J. 2017. Laterality and grip strength influence hand bone micro-architecture in modern humans, an HRpQCT study. Journal of Anatomy 230:796-804.

Riepert T, Drechsler T, Schild H, Nafe B, and Mattern R. 1996. Estimation of sex on the basis of radiographs of the calcaneus. Forensic Science International 77:133-140.

Robira B, Pouydebat E, San-Galli A, Meulman EJM, Aubaile F, Breuer T, and Masi S. 2018. Handedness in gestural and manipulative actions in male hunter-gatherer Aka pygmies from Central African Republic. American Journal of Physical Anthropology:n/a-n/a. 10.1002/ajpa.23435

Rodgers MM. 1988. Dynamic biomechanics of the normal foot and ankle during walking and running. Physical Therapy 68:1822-1830.

Ruff C. 1987a. Sexual dimorphism in human lower limb bone structure: relationship to subsistence strategy and sexual division of labor. Journal of Human Evolution 16:391-416. https://doi.org/10.1016/0047-2484(87)90069-8 
937 Ruff C, Holt B, and Trinkaus E. 2006. Who's afraid of the big bad Wolff?: "Wolff's law" and

938 bone functional adaptation. American Journal of Physical Anthropology 129:484-498.

939 10.1002/ajpa.20371

940

941

942

950

951

952

953

954

955

956

957

958

959

960

961

962

963

964

965

966

967

968

969

970

Ruff CB. 1987b. Sexual dimorphism in human lower limb bone structure: relationship to subsistence strategy and sexual division of labor. Journal of Human Evolution 16:391-416.

Ruff CB. 1987c. Structural allometry of the femur and tibia in Hominoidea and Macaca. Folia Primatol 48:9-49.

Ruff CB. 2000. Body size, body shape, and long bone strength in modern humans. Journal of Human Evolution 38:269-290. https://doi.org/10.1006/jhev.1999.0322

Ruff CB, and Larsen CS. 2014. Long Bone Structural Analyses and the Reconstruction of Past Mobility: A Historical Review. In: Carlson KJ, and Marchi D, eds. Reconstructing Mobility: Environmental, Behavioral, and Morphological Determinants. Boston, MA: Springer US, 1329.

Sahlins MD. 1968. Notes on the original affluent society. In: Lee RB, and DeVore I, eds. Man the Hunter. Chicago: Aldine, 85-89.

Schaffler MB, Burr DB, Jungers WL, and Ruff CB. 1985. Structural and mechanical indicators of limb specialization in primates. Folia Primatologic 45:61-75.

Shakked RJ, Walters EE, and O'Malley MJ. 2017. Tarsal navicular stress fractures. Current Reviews in Musculoskeletal Medicine 10:122-130.

Shaw CN, and Stock JT. 2009. Intensity, repetitiveness, and directionality of habitual adolescent mobility patterns influence the tibial diaphysis morphology of athletes. American Journal of Physical Anthropology 140:149-159. 10.1002/ajpa.21064

Smith HM. 2008. Degenerative Join Disease in the Windover Population MA. The Florida State University.

Smith RJ, and Cheverud JM. 2002. Scaling of sexual dimorphism in body mass: A phylogenetic analysis of Rensch's Rule in primates. International Journal of Primatology 23:1095-1135.

Smith RK. 2003. The Analysis of Skeletal Fractures From Windover (8Br246) and Their Inference Regarding Lifestyle MS. The Florida State University.

Sokal RR, and Rohlf FJ. 1995. Biometry: The Principles and Practice of Statistics in Biological Research. New York: W.H. Freeman and Company.

Steckel RH, and Rose JC. 2002. The Backbone of History: Health and Nutrition in the Western Hemisphere. Cambridge: Cambridge University Press.

Steele D. 1970. The talus and calcaneus: discriminant functions for estimation of sex among American Whites and Negroes. University of Kansas. 
971 Steele D. 1976. The estimation of sex on the basis of the talus and calcaneus. American Journal

972 of Physical Anthropology 45:581-588.

973 Steele DG, and McKern TW. 1969. A method for assessment of maximum long bone length and living stature from fragmentary long bones. American Journal of Physical Anthropology 31:215-228.

Stock JT. 2006. Hunter-gatherer postcranial robusticity relative to patterns of mobility, climatic adaptation, and selection for tissue economy. American Journal of Physical Anthropology

978 131:194-204. 10.1002/ajpa.20398

979

Stock JT, Shirley MK, Sarringhaus LA, Davies TG, and Shaw CN. 2013. Skeletal evidence for

980

981 variable patterns of handedness in chimpanzees, human hunter-gatherers, and recent British populations. Annals of the New York Academy of Sciences 1288:86-99. 10.1111/nyas. 12067

982

Trinkaus E. 1983. Neandertal postcrania and the adaptive shift to modern humans. In: Trinkaus E, ed. The Mousterian legacy: Human biocultural changes in the Upper Pleistocene. Oxford: British Archaeological Reports International Series, 165-200.

Trinkaus E, and Shang H. 2008. Anatomical evidence for the antiquity of human footwear. Journal of Archaeologial Science 35:1928-1933.

Tuross N, Fogel ML, Newsom L, and Doran GH. 1994. Subsistence in the Florida Archaic: The Stable-Isotope and Archaeobotanical Evidence from the Windover Site. American Antiquity 59:288-303. 10.2307/281933

990

991

992

Venkataraman VV, Kraft TS, Desilva JM, and Dominy NJ. 2013. Phenotypic plasticity of climbing-related traits in the ankle joint of great apes and rainforest hunter-gatherers. Human Biology 85:309-328. 10.3378/027.085.0315

Vignais N, Weresch J, and Keir PJ. 2016. Posture and loading in the pathomechanics of carpal tunnel syndrome: a review. Critical Reviews in Biomedical Engineering 44:398-410.

Waguespack N. 2005. The organization of male and female labor in foraging societies:

Waldron T. 1991. The prevalence of, and relationship between, some spinal diseases in a human skeletal population from London. Int J Osteoarchaeol 1:103-110.

999 Waldron T, and Rogers J. 1991. Inter-observer variation in coding osteoarthritis in human skeletal remains. Int J Osteoarchaeol 1:49-56. populations: California Amerinds and British Columbian Amerinds. American Journal of Physical Anthropology 140:19-24. 10.1002/ajpa.21025 
1004 Weiss E. 2012. Calcaneal spurs: Examining etiology using prehistoric skeletal remains to 1005 understand present day heel pain. The Foot 22:125-129.

1006 https://doi.org/10.1016/j.foot.2012.04.003

1007 Wentz RK. 2006. A Bioarchaeological Assessment of Health from Florida's Archaic:

1008 Application of the Western Hemisphere Health Index to the Remains from Windover 1009 (8Br246). MA. The Florida State University.

1010 Wentz RK. 2010. Patterns of degenerative joint disease among males and females at Windover 1011 (8BR246) tha their relationship to grave goods. The Florida Anthropologist 32:6-10.

1012 Wentz RK, and Gifford JA. 2007. Florida's deep past: The bioarchaeology of Little Salt Spring 1013 (8SO18) and its place among mortuary ponds of the Archaic. Southeastern Archaeology $1014 \quad 26: 330-337$.

1015 Wentz RK, Tucker B, Krigbaum J, and Doran GH. 2006. Gauging differential health among the 1016 sexes at Windover (8BR246) using the Western Hemisphere Health Index. Mem Inst Oswaldo 1017 Cruz, Rio de Janeiro 101:77-83.

1018 Wharton B, Ballo G, and Hope M. 1981. The Republic Groves Site, Hardee County, Florida. The 1019 Florida Anthropologist 34:59-80.

1020 Zverev YP. 2006. Spatial parameters of walking gait and footedness. Annals of Human Biology 1021

1022 33:161-176. 10.1080/03014460500500222

1023 
Table $\mathbf{1}$ (on next page)

Description of Measurements on Carpal and Tarsal Bones 
1 Table 1. Description of Measurements on Carpal and Tarsal Bones

\begin{tabular}{|c|c|c|}
\hline Variable & Orientation & Description \\
\hline Scaphoid length & proximal & scaphoid tubercle-lateral most point \\
\hline Scaphoid width & palmar & bisection of scaphoid ridge \\
\hline Capitate length & $\begin{array}{l}\text { medial } \\
\text { palmer }\end{array}$ & proximal-distal end \\
\hline Capitate width & lateral & thinnest point \\
\hline Lunate length & proximal & proximal-distal end \\
\hline Lunate width & proximal & medial-lateral sides \\
\hline Hamate length & lateral & proximal end-distal ridge (between metacarpal facets) \\
\hline Hamate width & lateral & most medial to most lateral side of the facet \\
\hline Calcaneus length ${ }^{1}$ & lateral & most posterior point of tuberosity to most anterior-superior point of cuboidal facet ${ }^{2}$ \\
\hline Calcaneus width ${ }^{1}$ & superior & $\begin{array}{l}\text { minimum horizontal width through body taken anterior to the tuberosity and posterior to talar posterior } \\
\text { facet }^{2}\end{array}$ \\
\hline $\begin{array}{l}\text { Calcaneus load arm } \\
\text { length }^{1}\end{array}$ & superior & most posterior point of talar posterior articular surface to most anterior-superior point of cuboidal facet ${ }^{2}$ \\
\hline $\begin{array}{l}\text { Calcaneus load arm } \\
\text { width }^{1}\end{array}$ & superior & most lateral point of posterior articular surface to most medial point of sustentaculum tali ${ }^{2}$ \\
\hline Talus length ${ }^{1}$ & superior & $\begin{array}{l}\text { flexor hallucis longis muscle sulcus at posterior aspect of talus to most anterior point on articular surface } \\
\text { for navicular }{ }^{2}\end{array}$ \\
\hline Talus width ${ }^{1}$ & superior & most lateral point of articular surface for lateral malleolus to opposite point of tibial articular surface ${ }^{2}$ \\
\hline $\begin{array}{l}\text { Trochlea of the talus } \\
\text { length }{ }^{1}\end{array}$ & superior & anterior-posterior plane ${ }^{2}$ \\
\hline $\begin{array}{l}\text { Trochlea of the talus } \\
\text { width }^{1}\end{array}$ & superior & perpendicular to projected line for maximum length of the trochlea ${ }^{2}$ \\
\hline Navicular length ${ }^{3}$ & distal & medial tuberosity to lateral cuneiform facet \\
\hline Navicular width ${ }^{3}$ & inferior & between intermediate and medial cuneiform facets \\
\hline Int. cuneiform length ${ }^{3}$ & superior & proximal and distal midpoint \\
\hline Int. cuneiform width ${ }^{3}$ & superior & thickest middle portion \\
\hline
\end{tabular}




\section{Table 2 (on next page)}

Mean per variable for Ratio (L:W) and Index (logged L:W) variables 
1 Table 2: Mean per variable for Ratio $(\mathrm{L}: W)$ and Index (logged $\mathrm{L}: \mathrm{W})$ variables

\begin{tabular}{lrr} 
& Ratio value & Index value \\
Calcaneus Load Arm & 0.78 & -0.25 \\
Lunate & 0.99 & -0.03 \\
Talar-Trochlea & 1.02 & 0.02 \\
Intermediate Cuneiform & 1.08 & 0.08 \\
Talus & 1.23 & 0.21 \\
Hamate & 1.32 & 0.27 \\
Capitate & 1.85 & 0.61 \\
Navicular & 2.25 & 0.81 \\
Scaphoid & 2.47 & 0.90 \\
Calcaneus & 3.12 & 1.13 \\
\hline
\end{tabular}

2 


\section{Table $\mathbf{3}$ (on next page)}

Univariate results from GLM for tarsal variables 
1 Table 3: Univariate results from GLM for tarsal variables

\begin{tabular}{|c|c|c|c|c|c|c|c|c|c|c|c|c|}
\hline \multirow{7}{*}{ Weight-Bearing } & \multirow{3}{*}{$\begin{array}{l}\text { Test } \\
\text { Calcaneus Load Arm }\end{array}$} & \multirow[b]{2}{*}{$\mathbf{F}$} & \multirow[b]{2}{*}{ df } & \multirow[b]{2}{*}{ Sig } & \multirow[b]{2}{*}{$\eta \mathbf{p}$} & \multirow[b]{2}{*}{ Power } & \multirow[b]{2}{*}{ Sex } & \multirow[b]{2}{*}{ Mean } & \multirow[b]{2}{*}{ SE } & \multirow[b]{2}{*}{$\mathbf{n}$} & \multicolumn{2}{|c|}{$95 \%$ CI } \\
\hline & & & & & & & & & & & Lower & Upper \\
\hline & & 0.20 & 1 & 0.66 & 0.00 & 0.07 & Male & -0.25 & 0.01 & 28 & -0.28 & -0.224 \\
\hline & & & & & & & Female & -0.24 & 0.02 & 18 & -0.28 & -0.207 \\
\hline & Calcaneus & 5.70 & 1 & 0.02 & 0.12 & 0.65 & Male & 1.15 & 0.01 & 28 & 1.13 & 1.177 \\
\hline & & & & & & & Female & 1.11 & 0.02 & 14 & 1.08 & 1.139 \\
\hline & Talus & 0.03 & 1 & 0.88 & 0.00 & 0.05 & Male & 0.21 & 0.01 & 28 & 0.19 & 0.236 \\
\hline & & & & & & & Female & 0.21 & 0.01 & 14 & 0.18 & 0.239 \\
\hline & Trochlea & 0.00 & 1 & 0.96 & 0.00 & 0.05 & Male & 0.01 & 0.01 & 28 & -0.01 & 0.033 \\
\hline & & & & & & & Female & 0.01 & 0.01 & 14 & -0.02 & 0.04 \\
\hline Shock-Absorbing & Intermediate Cuneiform & 3.77 & 1 & 0.06 & 0.07 & 0.48 & Male & 0.07 & 0.01 & 34 & 0.05 & 0.086 \\
\hline & & & & & & & Female & 0.10 & 0.01 & 20 & 0.07 & 0.126 \\
\hline & Navicular & 1.12 & 1 & 0.30 & 0.02 & 0.18 & Male & 0.80 & 0.01 & 34 & 0.78 & 0.822 \\
\hline & & & & & & & Female & 0.82 & 0.01 & 20 & 0.79 & 0.847 \\
\hline
\end{tabular}

2 
Table 4 (on next page)

Univariate results from GLM for carpal variables 
1 Table 4: Univariate results from GLM for carpal variables

\begin{tabular}{|c|c|c|c|c|c|c|c|c|c|c|c|c|c|}
\hline \multirow[b]{3}{*}{ Capitate } & \multirow[b]{2}{*}{ Levene } & \multirow[b]{2}{*}{ Sig } & \multirow[b]{2}{*}{$\mathbf{F}$} & \multirow[b]{2}{*}{ df } & \multirow[b]{2}{*}{ Sig } & \multirow[b]{2}{*}{$\eta \mathbf{p}$} & \multirow[b]{2}{*}{ Power } & & \multirow[b]{2}{*}{ Mean } & \multirow[b]{2}{*}{ SE } & \multicolumn{3}{|c|}{$95 \% \mathrm{CI}$} \\
\hline & & & & & & & & & & & $\mathbf{n}$ & Lower & Upper \\
\hline & 3.22 & 0.09 & 2.85 & 1 & 0.11 & 0.13 & 0.36 & M & 0.60 & 0.02 & 28 & 0.56 & 0.63 \\
\hline & & & & & & & & $\mathrm{F}$ & 0.65 & 0.02 & 21 & 0.60 & 0.70 \\
\hline Hamate & 2.15 & 0.16 & 1.11 & 1 & 0.31 & 0.05 & 0.17 & M & 0.28 & 0.02 & 21 & 0.24 & 0.32 \\
\hline & & & & & & & & $\mathrm{F}$ & 0.25 & 0.02 & 14 & 0.20 & 0.30 \\
\hline Lunate & 4.32 & 0.05 & 2.71 & 1 & 0.12 & 0.12 & 0.35 & M & -0.08 & 0.03 & 27 & -0.15 & -0.01 \\
\hline & & & & & & & & $\mathrm{F}$ & 0.01 & 0.04 & 20 & -0.08 & 0.10 \\
\hline Scaphoid & 0.22 & 0.64 & 1.10 & 1 & 0.31 & 0.05 & 0.17 & M & 0.85 & 0.03 & 22 & 0.79 & 0.92 \\
\hline & & & & & & & & $\mathrm{F}$ & 0.91 & 0.04 & 19 & 0.82 & 1.00 \\
\hline
\end{tabular}

2 
Figure 1

Boxplot of navicular raw length and width measurements by sex $(A)$; Boxplot of navicular index values by sex (B)

(A) Each data point for the navicular represents an individual length (shaded boxplot) or width value (unshaded boxplot); males and females are displayed separately. (B) Each data point for the navicular represents an individual logged ratio index value; males and females are displayed separately.

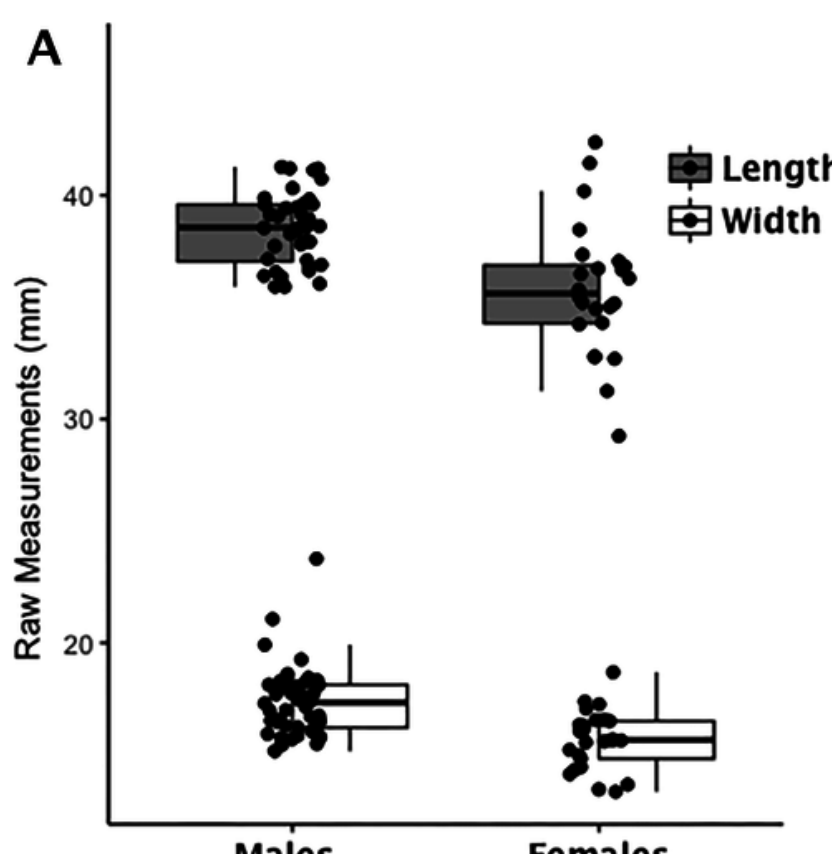

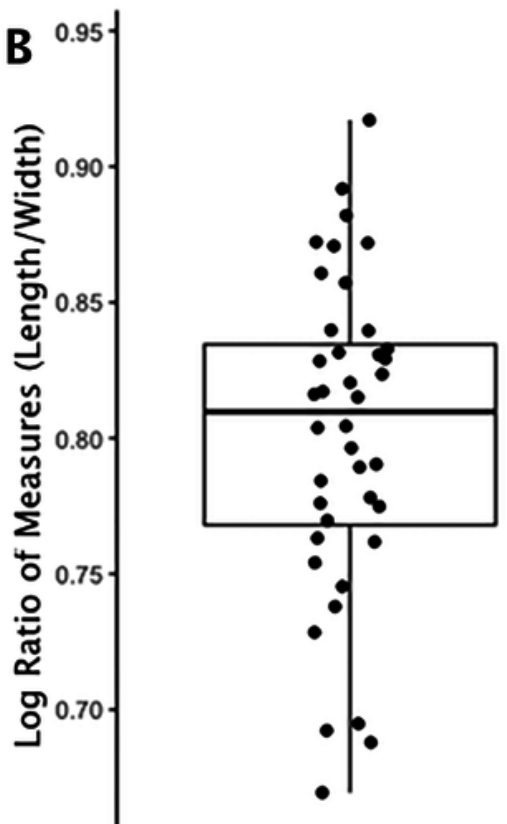

Males

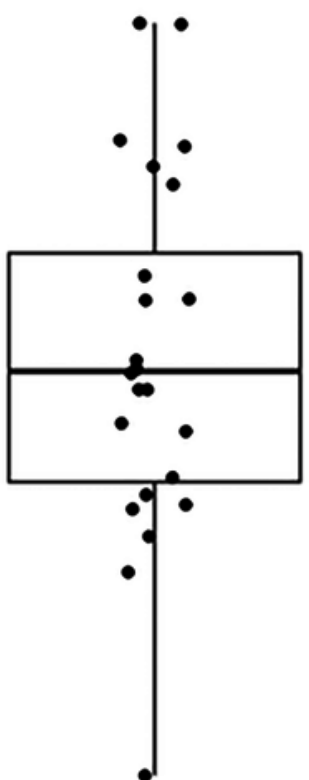

Females 
Figure 2

Boxplot of weight-bearing tarsal variables (talus, calcaneus) by sex

Each data point represents an individual index value (y-axis) for each of the four weight-bearing index variables on the $\mathrm{x}$-axis. Male boxplots are shaded; female boxplots are not shaded.

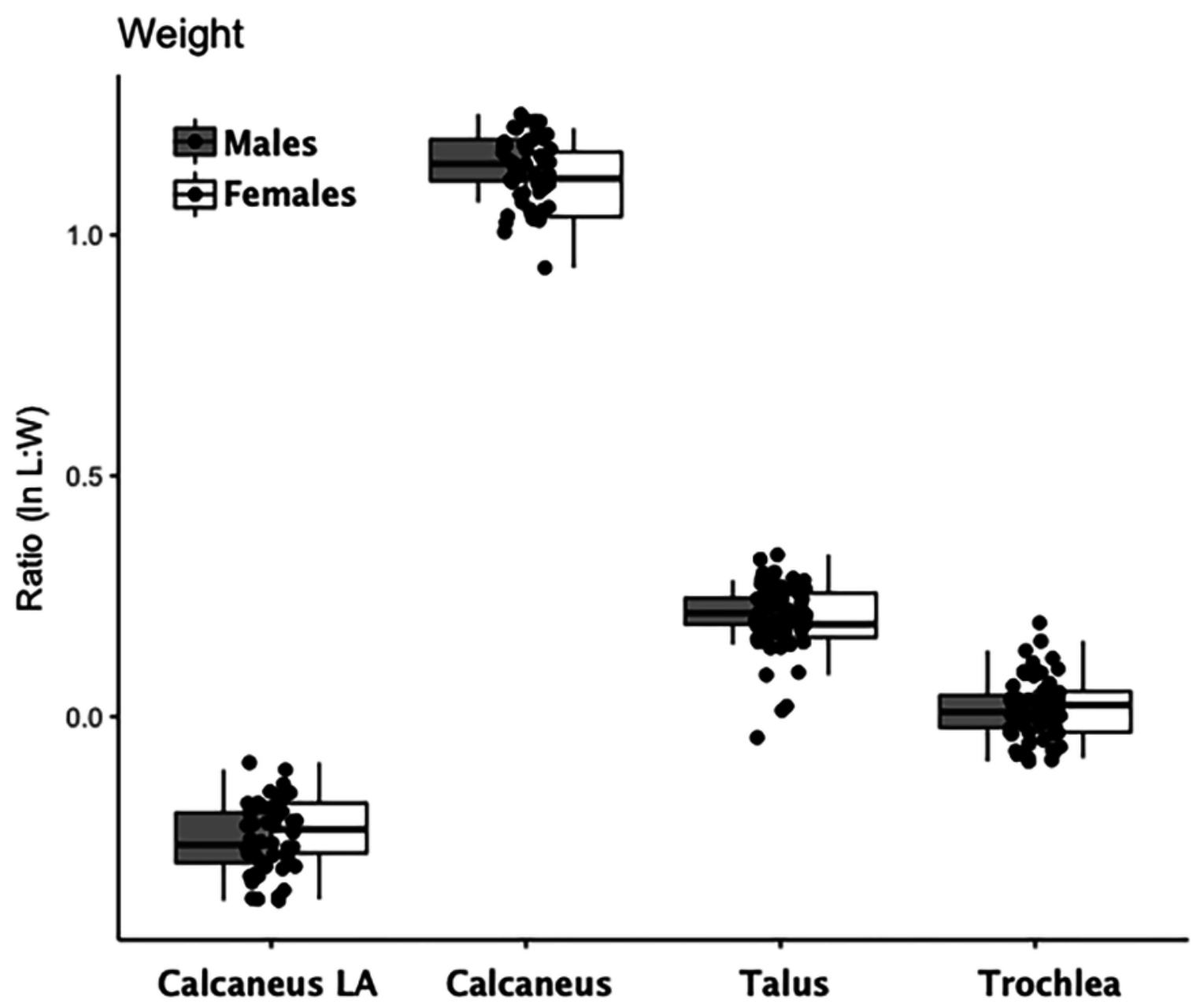


Figure 3

Boxplot of shock-absorbing tarsal variables (navicular, intermediate cuneiform) by sex

Each data point represents an individual index value (y-axis) for two shock-bearing index variables on the x-axis. Male boxplots are shaded; female boxplots are not shaded.

\section{Shock Absorbing Bones by Sex}

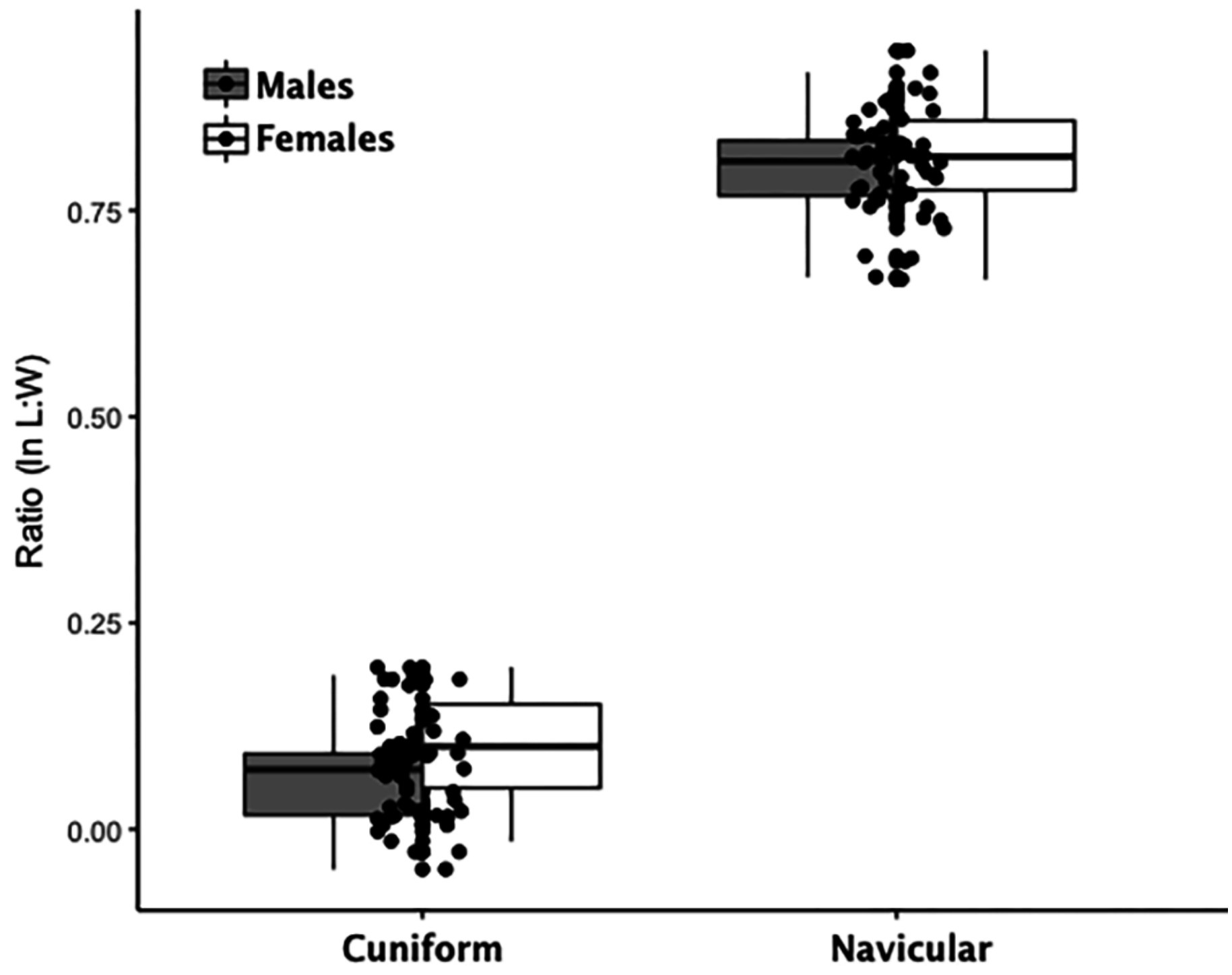

